\title{
OPEN ACCESS JOURNAL BDJ OPEN PUBLISHES FIRST PAPERS
}

BDJ Open, the new peer-reviewed, open-access, online-only journal for international dental and oral health, will publish its first articles today.

The opening papers, which are free to access, are prime examples of the new journal's broad scope, covering topics such as tooth extraction education at European dental schools and fixed bridge stability measurement.

The first articles include an editorial by the Editor-in-Chief, Stephen Hancocks OBE, who comments: 'The launch of BDJ Open is an exciting new development for the British Dental Association, for our publishing partners of 18 years, Nature Publishing Group and, we earnestly believe, for the dental world in general. On top of extensive international visibility and competitive turnaround times, it will offer authors an enriched digital publishing experience with industry-leading features such as article-level metrics, including data from Altmetric, and enhanced article layout and navigation.'

David Bull, Editorial Director, Academic Journals at Nature Publishing Group, said: 'BDJ Open is an excellent addition to the already strong British Dental Association portfolio of publications. At a time when an increasing number of research funding bodies are mandating open standards, we're delighted to be offering the international dental research community a state-of-the-art open access experience.'

The journal will cover dental materials science, dental public health, restorative dentistry, periodontology, and more.

$B D J$ Open is open for submissions, with the competitive article processing charge set at $£ 1,300$. Visit www.nature.com/bdjopen/ authors-and-referees/online-submission.

\section{BRINGING SMILES ACROSS NEPAL}

Earlier this year the North East based charity Smiles Across Nepal completed a two-week charity mission to the Himalayas. The charity raised over $£ 10,000$ to equip four new dental clinics for remote villages. These clinics will be used to provide dental outreach by trained staff at the new Dhulikhel Dental Hospital.

The charity, originally formed in 2013 by a group of passionate dentists, following a trip to Nepal, built links with the Nepalese hospital. The main aim of Smiles Across Nepal is to provide dental awareness and education, and enable long-term prevention and the treatment of common dental diseases in remote Himalayan communities. The charity has also instigated a UK approved programme to train Nepalese staff.

The 2015 trip was led by a group of dentists, along with staff at the new Dhulikhel Dental Hospital. The group included the winner of the 2014 Miss Newcastle competition, Ashley Gittins, who attended with a companion from Tyne Tees Models and both provided excellent oral health instruction to local villagers.

During the trip, dentists Dr Sanjeeb Nepali, Dr Mary Connolly and Dr Kirpal Benawara gave a series of interactive talks which were well received by Dhulikhel staff and students. Dr Rajendra Koju, Dental Director, and Dr Ram Shrestha, Dean of the Dhulikhel Hospital, were delighted for links to be established with the UK.

On the following days, the group travelled to remote Himalayan locations in jeeps; opening clinics and delivering oral health education to local schools and villages. Free dental camps were established at each centre during the visit.

\section{SECOND ORAL HEALTH ATLAS LAUNCHED}

FDI released the second edition of its Oral Health Atlas at the 2015 Annual World Dental Congress in Bangkok, Thailand. The new edition, called The Challenge of Oral Disease - A call for global action, serves as an advocacy resource for all oral healthcare professionals and anyone with an interest in oral health.

The Challenge of Oral Disease - A call for global action is aimed at dental associations, health organisations and the general public to provide them with the means they need to address policy makers, and advocate change in oral health related policies.

\section{DATES FOR THE DIARY REGIONAL AGMS}

Eastern Counties Branch AGM will be held on Wednesday, 11 November 2015, at Ravenwood Hall, Rougham, IP30 9JA, after the Branch Council Meeting which starts at $6.30 \mathrm{pm}$. For further information or to send in apologies, please contact Malcolm Heath at mlheath@aol.com.

South Wales Branch will be holding their Annual General Meeting on Friday, 20 November 2015 at the Vale Resort, Morgannwg Suite, Hensol Park, Hensol, CF72 8JY at $1.30 \mathrm{pm}$. The AGM will be followed by the Branch Study afternoon. All queries, confirmation of attendance or apologies to John Perry, Branch Secretary at bdasouthwales@gmail.com.

Sadly, following the trip a large Earthquake hit the Kathmandu Valley and unfortunately many areas visited by the charity were affected. Since the earthquake, however, Smiles Across Nepal has been working hard to raise both initial funds as well as money to help the long term rebuilding of affected dental outreach clinics. A recent charity walk to Scafell Pike, led by keen fundraisers, raised $£ 4,100$.

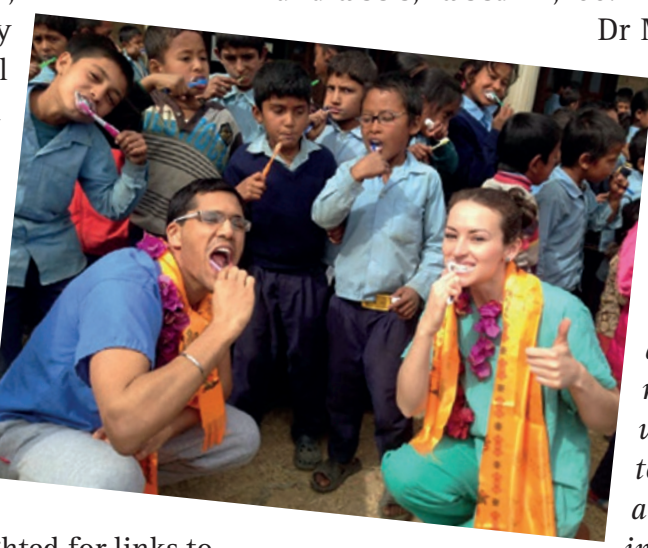

Dr Mary Connolly, one of the volunteers, said: 'I feel honoured to be a part of Smiles Across Nepal, the hard work and dedication to fundraising has been well received. Following the 2015 Earthquake we are now even more determined to support this unique country in helping to re-build areas affected, and continuing to drive the improvement in access to oral health for rural communities.'

Smiles Across Nepal is now expanding across the UK and appealing for new members to be a part of their ongoing work. They are also able to offer elective programmes to UK dental undergraduates, with a minimal charitable donation.

If you want to get involved, please visit www.smilesacrossnepal.co.uk 